ORIGINAL ARTICLE

\title{
Experience of Management of Vesicovaginal Fistula in Khairpur Medical College Hospital Khairpur
}

\author{
HAMEED-UR-RAHMAN BOZDAR ${ }^{1}$, SABAHAT FATIMA², INAYAT ULLAH MEMON ${ }^{3}$, WASIM SARWAR BHATTI ${ }^{4}$, NAEEM- \\ UL-KARIM BHATTI ${ }^{5}$, IMRAN KHAN MEMON ${ }^{6}$ \\ ${ }^{1}$ Assistant Professor of Urology, Khairpur Medical College, Khairpur Mir's \\ ${ }^{2}$ Assistant Professor of Obstetrics and Gynaecology, GMMMC Sukkur \\ ${ }^{3}$ Assistant Professor of Radiology GMMMC Sukkur \\ ${ }^{4}$ Associate Professor of Urology, Gambat Institute of Medical Sciences, Gambat \\ ${ }^{5}$ Assistant Professor of General Surgery PUMHS Nawabshah \\ ${ }^{6}$ Senior Registrar, Department of Radiology GMMMC, Sukkur \\ Correspondence to Dr. Sabahat Fatima Shah E-mail: sabamusavi12@gmail.com Cell: 0301-8119288
}

\begin{abstract}
Aim: To report the experience of vesicovaginal fistula repair among patients attending Khairpur Medical College. Study design: Retrospective cross-sectional study

Place and duration of study: Department of Urology, Khairpur Medical College Khairpur Mir's and Department of Obstetrics \& Gynaecology, GMMC, Sukkur from $1^{\text {st }}$ February 2018 to $20^{\text {th }}$ November 2020.

Methodology: Thirty five known case of vesicovaginal fistula presenting with continuous leakage of urine were consecutively included. Patients with failed previous repair were also included. After pre-operative work-up, fistula repair was done either through abdominal or vaginal route in two layers tension free and watertight with absorbable suture. All patients were called for follow-up visits at two weeks initially and then depending on the presence of symptoms later on.
\end{abstract}

Results: Transabdominal repair was observed in 18 (51.4\%) patients whereas transvaginal vesicovaginal repair in $17(48.6 \%)$ patients. The mean operative time was significantly higher among patients with transabdominal repair than transvaginal repair $(p<0.001)$. Similarly, mean estimated blood loss was significantly higher in transabdominal repair than transvaginal repair $(p<0.001)$. Success was found in majority of the patients $30(85.7 \%)$. Success was found significantly higher among patients with transabdominal repair as compared to transvaginal repair, $18(100 \%)$ vs $12(70.6 \%)(p=0.013)$.

Conclusion: Success rate of vesicovaginal repair was reported in majority of the patients. Though, success rate was remarkably higher in transabdominal repair, less estimated blood loss and operative time was reported in transvaginal repair.

Keywords: Vesicovaginal repair, Success rate, Transabdominal repair, Estimated Blood Loss, operative time,

\section{INTRODUCTION}

Vesicovaginal fistula is the most common type of acquired urogenital fistulae. It creates high psychological morbidity and causes social embarrassment to the patient. ${ }^{1}$ The reported incidence and aetiology differ between developed and developing nations. ${ }^{2,3}$ The incidence in the developed world is estimated between $0.3 \%$ and $2 \%$ with gynaecological surgery being the most common cause. ${ }^{4}$ In the developing world, the World Health Organization has estimated that on average one million women have vesicovaginal fistula with prolonged or obstructed labour being the leading cause. ${ }^{3}$ Epidemiologic data suggest that in low resourced areas, up to three million women living with vesicovaginal fistula require operative treatment. ${ }^{5}$

Various approaches to surgical repair have been described in the literature. Both transabdominal and transvaginal approaches are common surgical procedures. Published evidence demonstrate that the overall success rate after surgical repair varies in more than $80 \%$ in most of the cases regardless of through abdominal or vaginal approach. ${ }^{6-8}$ In fact, the optimum approach for repair is still disputable. While the anatomical closure rate following both

Received on 07-02-2021

Accepted on 17-06-2021 the procedures seems comparable ${ }^{9}$, there is a dearth of literature on the management of vesicovaginal fistula from Pakistan. Therefore, this study was planned to report the experience of vesicovaginal fistula repair among patients attending Khairpur Medical College, Khairpur Mir's.

\section{MATERIALS AND METHODS}

This retrospective cross-sectional study was conducted at Department of Urology, Khairpur Medical College Khairpur Mir's and Department of Department of Obstetrics \& Gynaecology, GMMC, Sukkur from $1^{\text {st }}$ February 2018 to $20^{\text {th }}$ November 2020. Thirty five known case of vesicovaginal fistula presenting with continuous leakage of urine were consecutively included. Moreover, patients with failed previous repair were also included. However, vesicovaginal fistula with involvement of urethra, ureter, uterine or rectum were excluded. Other urinary fistulas including vesicouterine, urethrovaginal, and ureterovaginal fistulas were also excluded. The detailed history, clinical examinations, and investigations (cystogram and cystoscopy) were retrieved from the hospital record. Intravenous urography was performed to assess the upper urinary tract. Percutaneous nephrostomy was carried out to divert the urine among patients with moderate to severe hydroureteronephrosis. Routine laboratory investigations like hemogram, renal function tests, liver function tests, 
total protein level, and serum albumin level were performed. Before the operation, emphasis on improvement of the nutritional status is given, and time interval is maintained between the operations.

After pre-operative work-up, fistula repair was done either through abdominal or vaginal route in two layers tension free and watertight with absorbable suture, which was decided by the type, size, number and site of the fistula. The patients were kept on antibiotics in the early post-operative period and then discharged with indwelling catheter for two weeks. As per the departmental protocol, all patients were called for follow up visits at two weeks initially and then depending on the presence of symptoms later on. The demographic characteristics of the patients along with nature of fistula, route of surgery and outcomes of repair were noted.

The data was entered and analyzed through SPSS24. The mean difference of quantitative variables among patients with transabdominal repair and transvaginal repair was explored using independent t-test. In addition, Chisquare/Fisher-Exact test was applied to see the association of transabdominal and transvaginal vesicovaginal fistula repair. The $p$-value of less than equal to 0.05 was considered as significant.

\section{RESULTS}

The mean age of the patients was $31.34 \pm 4.09$ years. The mean weight, height, and BMl of the patients were $60.71 \pm 5.24 \mathrm{~kg}, 1.54 \pm 0.06 \mathrm{~m}$ and $26.54 \pm 5.52 \mathrm{~kg} / \mathrm{m}^{2}$ respectively. The mean size of the fistula was $4.16 \pm 1.38$ $\mathrm{cm}$. Transabdominal repair was observed in $18(51.4 \%)$ patients whereas transvaginal vesicovaginal repair in 17 $(48.6 \%)$ patients. An insignificant mean difference of age $(p=0.508)$, weight ( $p$-value 0.533), height $(p=.643)$, and BMI (p-0.183) was observed among patients with vesicovaginal fistula. However, mean size of the fistula was significantly higher among patients with transabdominal vaginal repair compared to transvaginal vesicovaginal repair, $4.89 \pm 1.31$ $\mathrm{cm}$ vs. $3.39 \pm 1.01 \mathrm{~cm}(\mathrm{p}<0.001)$. Multiple vesicovaginal fistula was found significantly higher among patients with transabdominal vesicovaginal repair than that of those with transvaginal vesicovaginal repair, $15(83.3 \%)$ vs $5(29.4 \%)$ $(p=0.002)$. Site of vesicovaginal fistula also showed that supra trigonal site was significantly higher among patients transvaginal vesicovaginal repair as compared to those with trigonal vesicovaginal fistula, $17(100 \%)$ vs 11 (61.1), $\mathrm{p}=0.004$ [Table 1].

Perioperative outcome showed that mean operative time was $128.42 \pm 24.08$ minutes. Moreover, mean estimated blood loss and catheterization time was found to be $127.62 \pm 23.37 \mathrm{ml}$ and $23.55 \pm 2.08$ minutes respectively. The mean operative time was significantly higher among patients with transabdominal repair than that of transvaginal repair, $150.0 \pm 7.78$ minutes and 105.6 \pm 9.53 minutes respectively $(\mathrm{p}<0.001)$. Similarly, the mean estimated blood loss was significantly higher patients with transabdominal repair than that of transvaginal repair, $142.3 \pm 21.45 \mathrm{ml}$ and $112.41 \pm 13.92 \mathrm{ml}$ respectively $(\mathrm{p}<0.001)$ (Table 2)

Success was found in majority of the patients 30 $(85.7 \%)$. In particular, success was found significantly higher among patients with transabdominal repair as compared to transvaginal repair, $18(100 \%)$ vs $12(70.6 \%)$ $\mathrm{p}=0.013$ (Table 3).
Table 1: Comparison of vesicovaginal fistula repair with baseline characteristics $(n=35)$

\begin{tabular}{|c|c|c|c|}
\hline Variable & Transabdominal & Transvaginal & P value $^{t}$ \\
\hline Age (years) & $30.89 \pm 3.72$ & $31.82 \pm 4.52$ & 0.508 \\
\hline Weight (kg) & $60.17 \pm 5.43$ & $61.29 \pm 5.14$ & 0.533 \\
\hline Height (m) & $1.54 \pm 0.06$ & $1.55 \pm 0.07$ & 0.643 \\
\hline BMI $(\mathrm{kg} / \mathrm{m} 2)$ & $25.32 \pm 5.36$ & $27.83 \pm 5.55$ & 0.183 \\
\hline Size of fistula $(\mathrm{cm})$ & $4.89 \pm 1.31$ & $3.39 \pm 1.01$ & $<0.001$ \\
\hline \multicolumn{4}{|l|}{ Etiology } \\
\hline Hysterectomy & $6(33.3 \%)$ & $7(41.2 \%)$ & \multirow{4}{*}{$0.925^{\ddagger}$} \\
\hline LSCS & $4(22.25)$ & $4(23.5 \%)$ & \\
\hline Prolonged Labor & $6(33.35)$ & $5(29.4 \%)$ & \\
\hline Trauma & $2(11.1 \%)$ & $1(5.9 \%)$ & \\
\hline \multicolumn{4}{|l|}{ Multiple VVF } \\
\hline Yes & $15(83.3 \%)$ & $5(29.4 \%)$ & \multirow{2}{*}{$0.002^{\ddagger}$} \\
\hline No & $3(16.7 \%)$ & $12(70.6 \%)$ & \\
\hline \multicolumn{4}{|l|}{ Site of VVF } \\
\hline Supra Trigonal & $11(61.1 \%)$ & $17(100 \%)$ & \multirow{2}{*}{$0.004^{\ddagger}$} \\
\hline Trigonal & $7(38.9 \%)$ & - & \\
\hline \multicolumn{4}{|c|}{ Previously failed vaginal repair } \\
\hline Yes & $5(27.8 \%)$ & $10(58.8 \%)$ & \multirow{2}{*}{$0.064^{\ddagger}$} \\
\hline No & $13(72.2 \%)$ & $7(41.2 \%)$ & \\
\hline
\end{tabular}

†Independent t-test applied, $\ddagger$ Chi-square test/Fisher-Exact test applied

Table 2: Comparison of vesicovaginal fistula with perioperative parameters $(n=35)$

\begin{tabular}{|l|c|c|c|}
\hline \multicolumn{1}{|c|}{ Preoperative parameters } & Transabdominal & Transvaginal & $\mathbf{P}^{\text {Opalue }}{ }^{\dagger}$ \\
\hline $\begin{array}{l}\text { Operative time } \\
\text { min) }\end{array}$ & $150.0 \pm 7.78$ & $105.6 \pm 9.53$ & $<0.001$ \\
\hline $\begin{array}{l}\text { Estimated blood } \\
\text { loss (ml) }\end{array}$ & $142.3 \pm 21.45$ & $112.41 \pm 13.92$ & $<0.001$ \\
\hline $\begin{array}{l}\text { Catheterization } \\
\text { time (min) }\end{array}$ & $23.36 \pm 1.95$ & $23.76 \pm .25$ & 0.574 \\
\hline Complications & \multicolumn{3}{|l|}{} \\
\hline $\begin{array}{l}\text { Minor abdominal wound } \\
\text { infection }\end{array}$ & $2(11.1 \%)$ & $2(11.8 \%)$ & $0.952 \ddagger$ \\
\hline Urinary tract infection & $3(16.7 \%)$ & $2(11.8 \%)$ & $0.679 \ddagger$ \\
\hline
\end{tabular}

tIndependent t-test applied, $\ddagger$ Chi-square test/Fisher-Exact test applied

Table 3: Success of vesicovaginal fistula and surgical approach $(\mathrm{n}=35)$

\begin{tabular}{|l|c|c|c|}
\hline Outcome & Transabdominal & Transvaginal & P value \\
\cline { 1 - 3 } Success & $18(100 \%)$ & $12(70.6 \%)$ & \multirow{2}{*}{0.013} \\
\hline Failure & - & $5(29.4 \%)$ & \\
\hline
\end{tabular}

\section{DISCUSSION}

This study was conducted with the aim to share the experience of management of vesicovaginal fistula among women residing in Khairpur which is the fifth largest populated district of Sindh. All known cases of vesicovaginal fistula reported in past three and half year was reported. The findings of the current study reported that mean operative time was found to be128.42 \pm 24.08 minutes. Moreover, mean estimated blood loss and catheterization time was found to be $127.62 \mathrm{ml}$ and 23.55 minutes respectively. Furthermore, according to the current study finding, the mean operative time was considerably higher among patients with transabdominal repair than that of transvaginal repair. Similarly, the mean estimated blood loss was significantly higher patients with transabdominal repair than that of transvaginal repair. Somewhat similar findings were reported in a recent study conducted by Panaiyadiyan et $\mathrm{al}^{10}$ in India in which authors have reported considerably higher mean operative time and estimated blood loss. 
In this study, multiple vesicovaginal fistula was found considerably higher among patients with transabdominal vesicovaginal repair than that of those with transvaginal vesicovaginal repair. Site of vesicovaginal fistula also showed that supra trigonal site was considerably higher among patients with transvaginal vesicovaginal repair as compared to those with trigonal vesicovaginal fistula.In contrast to the current study findings, Khalid et al in their study reported infratrigonal fistula in majority of the patients. ${ }^{11}$

Success was found in majority of the patients in the current study. In particular, success was found considerably higher among patients with transabdominal repair as compared to transvaginal repair. Similar to the current study finding, various other studies have also reported higher success rate of transabdominal vesicovaginal repair compared to transvaginal repair. ${ }^{12,13}$ However, in contrast to the current study findings, Panaiyadiyan et $\mathrm{al}^{10}$ in their study reported no significant difference in the success rate among women underwent transabdominal repair or transvaginal repair. It is reported in a previous study that radiation, ischemia of the tissue, and previously failed repair were the most common factors affecting the success rate of vesicovaginal fistula repair. ${ }^{6}$ In addition to this, combined approach of transabdominal and transvaginal repair had higher failure rate as reported by Pakistani study ${ }^{12}$. Most of the studies carried out in Pakistan have reported overall higher success in women surgically managed for vesicovaginal fistula repair. ${ }^{11,12,14,15}$

As far as the complications are concerned, the findings of the current study showed that urinary tract infection was found in majority of the patients followed by minor abdominal wound infection. Singh et $\mathrm{al}^{16}$ in their study reported prolonged paralytic ileus as the most common complications, followed by mild hematuria, minor abdominal wound infection, and urinary tract infection. A recent reported from Pakistan has also reported urinary tract infection as the most common infection followed by storage dysfunction, and wound infection. ${ }^{12}$

The findings of the current study could be highlighted in the light of limitation that this study was a retrospective study and this have missed most of the important variables due to no direct approach to the patients. Moreover, limited number of sample size was also one of the limitations of the current study. Despite of these limitations, the current study is of importance as the findings are shared from the Khairpur city. It is believed that inclusion of patients from multicentre and large number of potential variables will definitely the help in effective management and learning from previous experience. Future researches on management of vesicovaginal repair should focused on these aspects in future.

\section{CONCLUSION}

The management of vesicovaginal fistula repair requires close monitoring and experience in terms of decision on the transabdominal or transvaginal approach for the surgical repair. Though, success rate was remarkably higher in transabdominal repair in our cohort. However, less estimated blood loss and operative time was reported in patients underwent transvaginal repair. Late presentation with the disease and poor medical resources also worsen the management of vesicovaginal fistula in healthcare settings like ours.

\section{Conflict of interest: Nil}

\section{REFERENCES}

1. Adefris M, Abebe SM, Terefe K, Gelagay AA, Adigo A, Amare $S$, Lazaro D, Berhe A, Baye C. Reasons for delay in decision making and reaching health facility among obstetric fistula and pelvic organ prolapse patients in Gondar University hospital, Northwest Ethiopia. BMC Women's Health 2017;17(1):1-7.

2. Umeora OUJ, Emma-Echiegu NB. Vesico-vaginal fistula in developing countries - time to turn off the tap. J. Preg. Child Health 2015; 2: e120.

3. Ghoniem GM, Warda HA. The management of genitourinary fistula in the third millennium. Arab J Urol 2014;12:97-105.

4. Angioli R, Penalver M, Muzii L, Mendez L, Mirhashemi R, Bellati F. Guidelines of how to manage vesicovaginal fistula. Crit Rev Oncol Hematol 2003;48:295-304.

5. Medlen H, Barbier H. Vesicovaginal Fistula. StatPearls [Internet].

6. Rajaian S, Pragatheeswarane M, Panda A. Vesicovaginal fistula: Review and recent trends. Indian journal of urology: IJU 2019;35(4):250.

7. Malik MA, Sohail M, Malik MT, Khalid N, Akram A. Changing trends in the etiology and management of vesicovaginal fistula. IJU 2018;25(1):25-9.

8. Moses RA, Gormley EA. State of the art for treatment of vesicovaginal fistula. Curr Urol Reports 2017;18(8):1-7.

9. El-Azab AS, Abolella HA, Farouk M. Update on vesicovaginal fistula: a systematic review. Arab J Urol 2019;17(1):61-8.

10. Panaiyadiyan S, Nayyar BU, Nayyar R, Kumar N, Seth A, Kumar $\mathrm{R}$, et al. Impact of vesicovaginal fistula repair on urinary and sexual function: patient-reported outcomes over long-term follow-up. IJU 2021; 9:1-8.

11. Khalid M, Hassan MH, Asif M, Tariq QA.Outcome of primary repair of vesicovaginal fistula (VVF). JUMDC 2020;12(2):146151

12. Nizamuddin, Elahi F, Ali M, Akbar F, Hussain M, Gul S. Outcome of vesicovaginal fistula repair at Urology Department STH Swat. J Saidu Med Coll 2020;10(2).

13. Biswas M, Uddin SM, Sharifa J, Ghosa S, Bhuiyan AM, Ghosh KC. Repair of vesicovaginal fistula: Experiene of 30 Cases and Analysis of Outcome Predictors. Bangladesh $\mathrm{J}$ Urol 2019;22(2):136-40.

14. Jan MA, Ullah A. Management of Vesicovaginal Fistula: An Experience with 32 Cases. Ann Pak Inst Med Sci 2012;8(3):180-3.

15. Shakil M, Ahmed R, Hanif $S$. Surgical outcomes of genitourinary fistulae: an analysis of 26 cases. Pak J Physiol 2016;12(4):27-9.

16. Singh V, Sinha RJ, Mehrotra S, Sankhwar SN, Bhatt S. Repair of vesicovaginal fistula by the transabdominal route: outcome at a north Indian tertiary hospital. IJU 2012;23(4):411-6. 